\title{
Comparison of hygrothermal 2D- and 3D-simulation results with measurements from a test house
}

\author{
Ulrich Ruisinger ${ }^{1}$, Peter Kautsch ${ }^{2}$ \\ ${ }^{1}$ Technische Universität Dresden, Institut für Bauklimatik, 01062 Dresden, Germany \\ ${ }^{2}$ Technische Universität Graz, Institut für Hochbau, 8010 Graz, Austria
}

\begin{abstract}
This article examines whether transient two-dimensional simulations are sufficient or threedimensional simulations are necessary for the hygrothermal analysis of the three-dimensional detail of a beam support. Detailed measurement series from a test house with various interior insulation systems available for the investigation allow the results of two- and three-dimensional simulations to be verified with the measured data. In both the cases, a very good agreement between measurement and simulations was found. With the thermal simulations, agreement with the measured data is similar in both two- and three-dimensional calculations. However, the hygric measurements agreed slightly better with the three-dimensional calculations. For planning real tasks, two-dimensional simulations should be sufficient, provided that the simulation settings are selected within the secure margins. The actual comparison is initiated by the validation of the software DELPHIN 6 by means of a three-dimensional, stationary test case from EN 10211.
\end{abstract}

\section{Introduction}

Three-dimensional, thermal building component simulations have been established decades ago [1-3] and are generally used only for special applications due to greater efforts involved. Some of these software programs, specialised in the construction sector, also have the option of considering vapour transport [4]. Apart from a limited material model, these programs cannot consider important damage mechanisms such as driving rain or constructions with attached ground water. Hygrothermally coupled 3D building component simulations that take vapour, capillary and air transport into account under dynamic climatic conditions have been started only in recent years $[5,6]$. Such simulations require a comparatively high expenditure of time for input, calculation and evaluation. Therefore, many users are often faced with the choice of whether such 3D simulations are necessary at all.

A typical 3D detail that occurs frequently in historical buildings and which is often discussed, especially in connection with interior insulation, is the beam support in exterior walls. This article investigates whether 2D simulations are sufficient for this detail or 3D simulations are necessary.

\section{Previous activities}

Three-dimensional, transient, heat and moisture coupled simulations have rarely been carried out so far. After an adaptation to hygrothermal building simulation requirements, in [5] the multifunctional software package COMSOL Multiphysics ${ }^{\circledR}[7]$ was applied. However, such adaptions are often time consuming since all necessary climate and material data must be provided. In [5], the influence of rain could not be included as a corresponding model was missing. Despite the software's powerful numerics, this type of approach will be possible only for specialists or engineers with a certain time budget. Another Software [6] takes air transport into account, but is available only to a very limited number of users.

Both projects mentioned above were exemplary simulations without a real task in mind. Neither a comparison of simulation results with measurements was possible, nor was a comparison with results from 2D simulations carried out. Other 3D software programs generally lack the possibility to consider liquid water transport [1-4]. Within the research project on hygrothermal planning of building constructions [8] the DELPHIN software [9], which until then had only been calculating 2D and 3D rotationally symmetrical objects, was enabled to simulate transient rectangular 3D models. Furthermore, an anisotropic material model was introduced. A first validation of the numerical solver was done in the project [8] with the help of the measured data from two laboratory test benches. This software was used in this work. The measurement data and simulations for the examinations presented here were derived from a research project carried out at the Institute of Building Construction of TU Graz [10, 11].

\section{Validation of the software}

The general suitability of scientific models must be presented in a comprehensible and replicable manner before they are used for further applications. With the

\footnotetext{
* Corresponding author: ulrich.ruisinger@tu-dresden.de
} 
project HAMSTAD (Heat, Air and Moisture STAnDardization, [12]) the possibility was established to validate hygrothermal calculation models using benchmark tests. By means of five one-dimensional, partly transient test cases, one's numerical calculation results can be compared with the given ones. In the report [13] it is explained how these HAMSTAD benchmarks and further test cases from EN 15026 (1D hygrothermal, [14]), as well as EN ISO 10211 (2D thermal, [15]) are used to regularly check the DELPHIN software that has been used in this examination.

After the changes in the Software, however, it has become necessary to validate the numerics extended into the three-dimensional space. This could be realized with the results from the earlier project [8] and the EN ISO 10211 [15]. Two thermal 3D test reference cases are available in Annex C of EN ISO 10211 [15]. These are generally known, but "only" stationary cases make it at least possible to check the extended numerics with regard to thermal modelling. Here, the results of case 3 , the detail of an uninsulated balcony slab protruding from the wall of a building corner (Figure 1), from Annex C of [15] will be presented,.

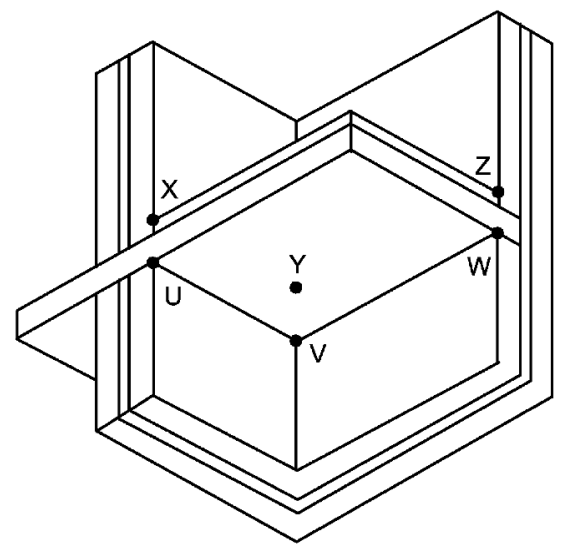

Fig. 1. Design for test case 3 from Annex C of EN 10211 [15].

EN ISO 10211 specifies the temperatures to be reached in the upper and lower corners of the room and the heat flow balances $\Phi$ for the individual climate zones $\alpha$ (upper room), $\beta$ (lower room) and $\gamma$ (outside). The differences between the calculated and prescribed temperatures may not exceed $0.1 \mathrm{~K}$ and the calculated heat flows may only deviate by a maximum of $1 \%$. Table 1 compares requirements from EN ISO 10211 [15] with the results of two simulations with DELPHIN 6 (D6). The maximum temperature difference occurred at the lower ceiling of the building with comparatively coarse discretization with $0.038 \mathrm{~K}$, with fine discretization it was $0.023 \mathrm{~K}(<0.1 \mathrm{~K})$. The maximum difference in the heat flow balance for the upper room was $0.25 \%$ with coarse discretization, with fine discretization it was only $0.02 \%$ deviation $(<1 \%)$. The requirements are thus met with good to excellent results, depending on the level of discretisation. Case 4 from [15] was also fulfilled with similar accuracy. The geometric model of the first simulation comprised 643,721 elements with a minimum element thickness of $1 \mathrm{~mm}$. In the second simulation there were 48,752 elements with a minimum element thickness of $3 \mathrm{~mm}$.

The 3D anisotropic simulations based on heat and moisture coupled numerics are much more complex than those for the cases mentioned so far, but no reference cases are available.

For this purpose, a benchmark test was newly developed for the validation of 3D anisotropic transport models (“ATBEB", [8]): a partially sealed wooden beam is exposed to moisture changes in a climate chamber and in the simulation under isothermal conditions. Thus, the extensions in the hygric numerics and in the anisotropy could be verified. As shown in the earlier project [8] the measurements were reproduced by the software with good agreement.

\section{Comparison of measurements with 2D and 3D simulation results}

The mathematical reproduction of measurement data with simulation software is usually easier with laboratory test benches compared to constructions in buildings. In various research projects on beam supports $[8,17,18]$, the components in the test stands were considerably simplified (no ceiling construction), took place under controlled climatic conditions (no driving rain, no radiation, simplified artificial climates) and all material properties were determined according to the state of the art. One exception to this is [19]. In the project OEKO-ID [10], the climatic conditions were available, but various imponderables existed, e.g. with regard to the properties of the existing materials.

During this project in a kindergarten in Graz, Austria, five diffusion-open interior insulation systems were installed in two rooms one above the other with a wooden beam ceiling in between.

Table 1. Prescribed results from EN 10211 compared with results of the software DELPHIN 6 (D6).

\begin{tabular}{|r|c|c|c|c|c|c|c|c|c|c|}
\hline & $\begin{array}{c}\text { Temp. } \\
\text { below } \alpha\end{array}$ & $\Delta$ in K & $\begin{array}{c}\text { Temp. } \\
\text { top } \beta\end{array}$ & $\Delta$ in $\mathrm{K}$ & $\begin{array}{c}\Phi_{\alpha} \\
\text { below }\end{array}$ & $\Delta$ in $\%$ & $\begin{array}{c}\Phi_{\beta} \\
\text { top }\end{array}$ & $\Delta$ in $\%$ & $\begin{array}{c}\Phi_{\gamma} \\
\text { exterior }\end{array}$ & $\Delta$ in $\%$ \\
\hline EN 10211 & 11.32 & - & 11.11 & - & 46.09 & - & 13.89 & - & 59.98 & - \\
\hline (1) D 6 & 11.3431 & 0.0231 & 11.1142 & 0.0042 & 46.0984 & 0.018 & 13.8918 & 0.013 & 59.9903 & 0.017 \\
\hline (2) D 6 & 11.3216 & 0.0016 & 11.0723 & 0.0377 & 46.0175 & 0.158 & 13.8558 & 0.247 & 59.8733 & 0.178 \\
\hline
\end{tabular}


Measured values of many sensors in and around eight beam supports were recorded over three condensation periods (Figure 2). Measurement series of seven insulated and partially sealed beam supports could thus be compared with an uninsulated beam support. This project was continued by comparing the measurements with $2 \mathrm{D}$ and 3D simulation results [11].

The activity of the building was not interrupted during the measurements, but the rooms were humidified during the second and third winter (up to $60 \%$ ), as the room air humidity repeatedly fell below $20 \%$. The plastered existing masonry was about $52 \mathrm{~cm}$ thick. The thermal conductivity of the solid bricks turned out to be unusually low at about $0.4 \mathrm{~W} /(\mathrm{m} \cdot \mathrm{K})$. During the planning phase, this led to a clear overestimation of the possible energy saving potential. The beam support presented here was insulated on the inside with $100 \mathrm{~mm}$ thick reed insulation boards (Figure 2). Masonry joints were neglected in the simulations.

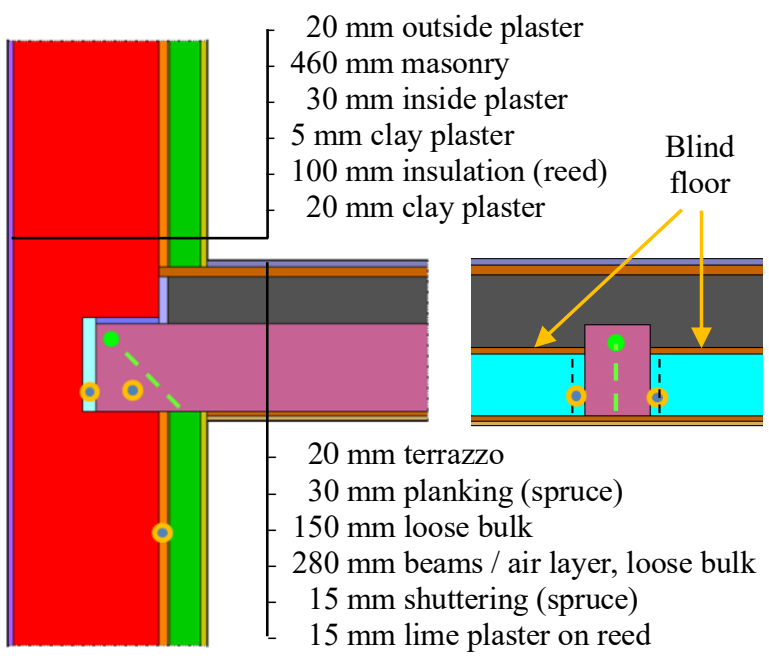

Fig. 2. Left section: through the ceiling beam (x-y axis); right section: through ceiling (y-z axis, screenshot software); position of the combined temperature/humidity sensors in orange/blue, diagonally drilled wood humidity sensors in green.

Six of the eight beam supports were carefully sealed under the blind floor. In contrast, no sealing measures took place on the upper side of the beams. No building rubble was found in the beam supports.

Two combined temperature/humidity sensors were placed in each of the beam supports: in front of the end grain and on the beam cheek. These were supplemented by approximately $0.4 \mathrm{~m}$ long wood moisture electrodes. They were inserted from the lower room by means of holes predrilled at an angle into the beams. As they were not insulated along their entire length, they measured the electrical resistance at the "wettest point". As could be shown earlier [11], this was at the end grain.

Here, the investigations are presented on the field insulated with reed, in which the beam was sealed under the blind floor (Figure 2). With the help of simulations of the undisturbed, 1D wall structures, it is possible to identify simulation settings such as thermal transition conditions and to revise material properties. As described in an earlier work [20], the software GenOpt helps with semi-automatised simulations to achieve quicker results. In the case of the perlite insulation board a higher design thermal conductivity of 0.047 instead of $0.045 \mathrm{~W} /(\mathrm{m} \cdot \mathrm{K})$ was found out. This is in better agreement with the measurements from the test house. Where the material properties are considered, for the perlite insulation board, the highest deviation was observed between the simulations and the manufacturer specifications [11]. For thermal and liquid transport in the other materials, the manufacturer specifications respectively laboratory measurements were used.

This phase of 1D simulations was followed by 2D and 3D simulations of the beam supports. The agreement of the simulation results with the measurements was generally very good, in both $2 \mathrm{D}$ and $3 \mathrm{D}$ simulations. Thus, in Figure 3, the three temperature curves in the air layer in front of the end grain are hardly distinguishable. To evaluate the divergence between measurements and simulations the difference between measurements and simulations averaged over the simulation period, 'AD' for short, and the standard deviation 's' are calculated.

$$
\begin{aligned}
& A D=\frac{\sum_{i=1}^{n}\left|\left(x_{\text {Simulation }}-x_{\text {measure }}\right)\right|}{n} \\
& S=\sqrt{\frac{\sum_{i=1}^{n}\left(x_{\text {Simulation }}-x_{\text {measure }}\right)^{2}}{n}}
\end{aligned}
$$

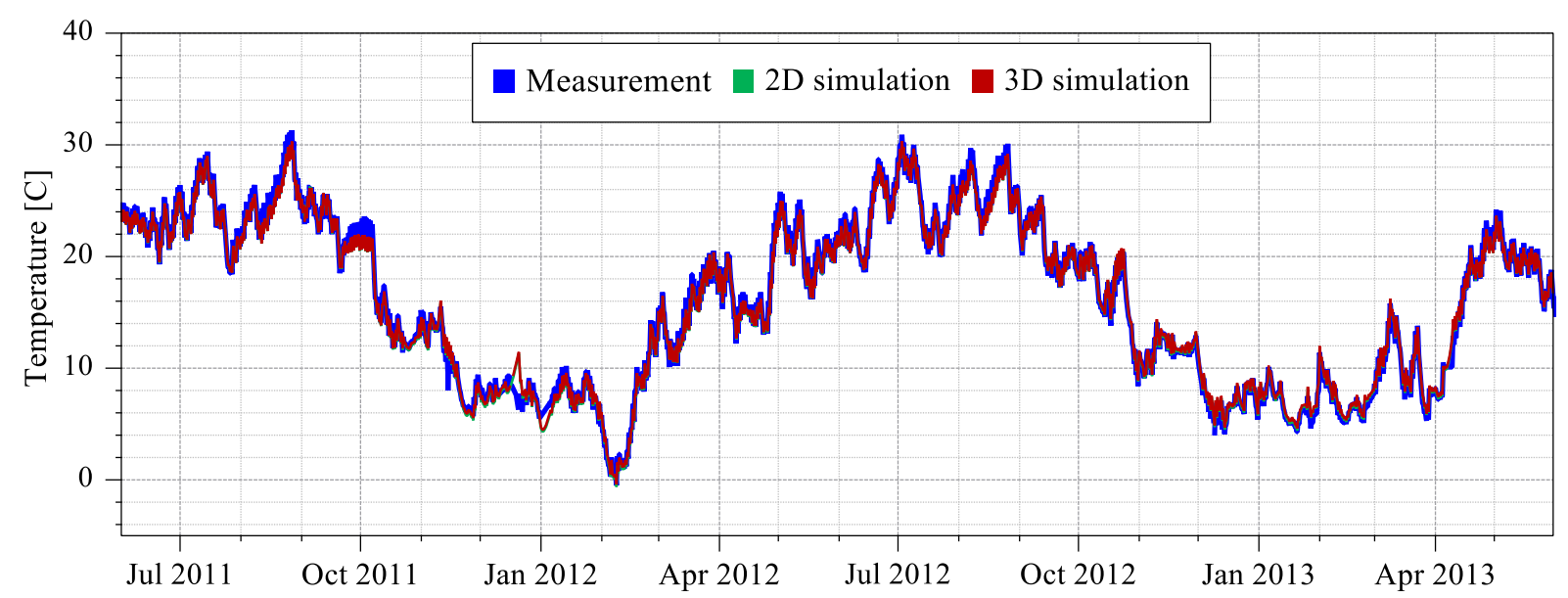

Fig. 3. Measured and calculated temperatures for the measuring position in the air layer in front of the end grain. 
In Figure 3 'AD' is only 0.4 kelvin and ' $\mathrm{s}$ ' is $0.5 \mathrm{~K}$. These differences occur regardless of whether the $2 \mathrm{D}$ or 3D simulation is applied, or whether the calculation was performed with or without the influence of air pressure differences. With a sensor accuracy of $\pm 0.4 \mathrm{~K}$, the agreement between measurement and calculation is therefore exceptionally good. Similar comparison data in other supports suggest that 3D simulations are not necessary for purely thermal-dynamic considerations.

With the absolute humidity in front of the end grain, the measurement and simulation results deviate more (Figure 4): the 2D simulation by an average $\mathrm{AD}$ of $1.1 \mathrm{~g} / \mathrm{m}^{3}\left(\mathrm{~s}=1.3 \mathrm{~g} / \mathrm{m}^{3}\right), 3 \mathrm{D}$ by $0.8 \mathrm{~g} / \mathrm{m}^{3}\left(\mathrm{~s}=1.0 \mathrm{~g} / \mathrm{m}^{3}\right)$. At the beam cheek (not shown) the differences were smaller, by $0.1 \mathrm{~g} / \mathrm{m}^{3}$ each [11]. The lower graphs in Figure 4 highlight timespans with higher deviation

In contrast to the temperatures, if the air pressure difference is taken into account an influence can be observed. No measurements were available for the permeabilities of the materials, so that they had to be estimated on the basis of the few available literature sources and simulations [11]. For the applied air pressure difference $\Delta \mathrm{P}$, the simplified proposal from WTA-leaflet [21] was adopted in a modified form. The only (time) variable quantity is the temperature difference between inside and outside air, $\mathrm{T}_{\mathrm{i}}$ and $\mathrm{T}_{\mathrm{e}}$ (in kelvin), as there was no additional, mechanically generated difference in pressure $\Delta \mathrm{P}_{\text {mech: }}$ :

$$
\Delta P=Q \cdot\left(T_{i}-T_{e}\right) / T_{i} \cdot g \cdot h / 2+\Delta P_{\text {mech }}
$$

Here, $\mathrm{h}$ is the height of the connected air space $(12 \mathrm{~m}$ in this building with open doors and staircases), $g$ the acceleration of gravity $\left(9.81 \mathrm{~m} / \mathrm{s}^{2}\right)$ and $\rho$ the density of air. In the simulations, to the outer surface, a constant air pressure is assigned and to internal surfaces hourly values of $\Delta \mathrm{P}$ from (3) are assigned. The model does not consider the influence of wind pressure. With this air pressure model, the difference in air humidity at the end grain is just as large as in the 3D simulation without airflow (AD $\left.=0.8 \mathrm{~g} / \mathrm{m}^{3}\right)$, but at the beam cheek the difference increases slightly due to the airflow (not shown).

Overall, the deviation from the measured values remains small at the absolute humidity (measuring accuracy of the sensors at $5^{\circ} \mathrm{C}$ is $\pm 0.3 \mathrm{~g} / \mathrm{m}^{3}$ and at $15^{\circ} \mathrm{C}$ it is $\pm 0.7 \mathrm{~g} / \mathrm{m}^{3}$ ). It is noticeable that, taking into account the difference in air pressure (light blue curve), the moisture load in the transition period in spring, especially from April to May or June, is overestimated.

The transition period is particularly interesting with regard to possible mould or fungal damage, as temperatures are higher during this period and thus more favourable for the growth of harmful organisms. The slight overestimation of the moisture input is therefore desirable for a safe planning.
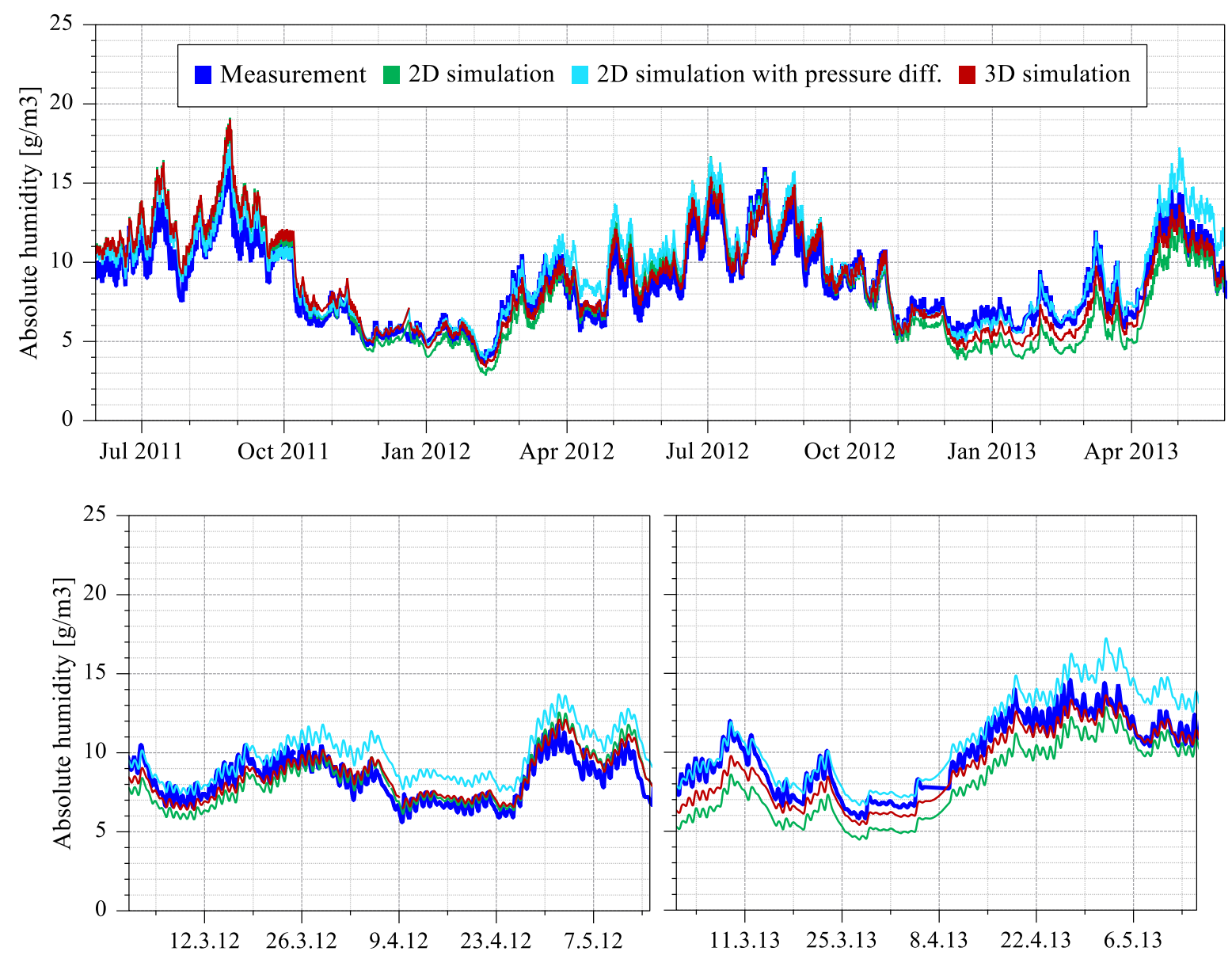

Fig. 4. Above: Measured and calculated absolute humidities for the measurement position in front of the end grain. Below: for the periods 1.3. to 15.5.2012 and 2013 with time spans of highest deviations. 


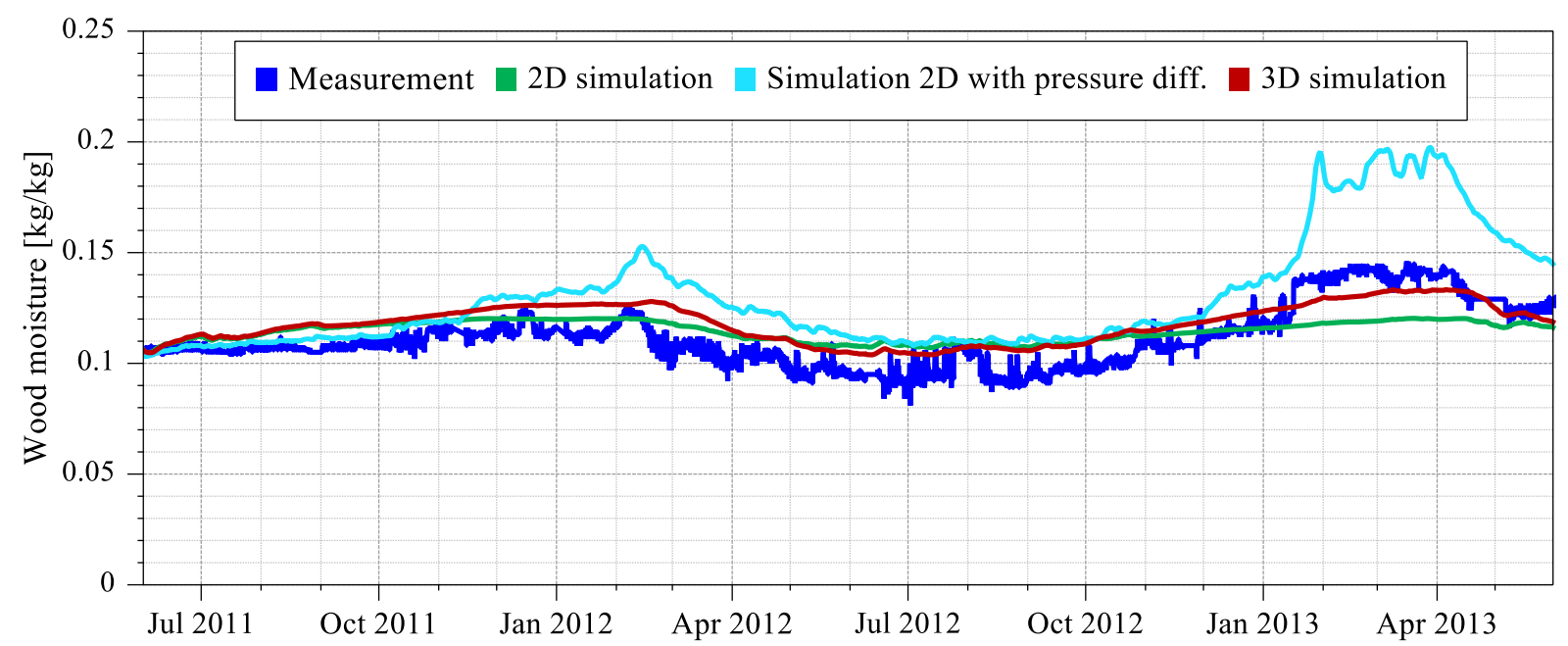

Fig. 5. Measured and calculated wood moisture content at a distance of approx. $10 \mathrm{~mm}$ from the end grain of the beam.

When comparing the wood moisture graphs (Figure 5), it becomes apparent that, especially in the case of very high indoor air humidity in winter/spring 2013, convective moisture inputs are highly overestimated when air pressure differences are taken into account (light blue curve). The same trend can also be observed in Figure 4, although less pronounced. The consideration of the air pressure model obviously leads here to an overestimation of the air or humidity input and should not be considered in this case. Averaged over the simulation period, all other simulations also overestimate the moisture development, but not as much as in the 2D simulations with air pressure. The $\mathrm{AD}$, in both the $2 \mathrm{D}$ and the $3 \mathrm{D}$ variant exceeded the measured curve by 0.01 and $0.009 \mathrm{~kg} / \mathrm{kg}$ respectively. At times, the wood moisture content of the curve with air flow exceeded the measuring accuracy of $\pm 0.015 \mathrm{~kg} / \mathrm{kg}$ by $100 \%$ in the second winter.

The erratic behaviour of the measured values (dark blue) in Figure 5 arise from peculiarities of the sensor used. Another reason could be that the sorption isotherm of the spruce in the test house has a higher slope. However, this was not verified as the properties of the spruce were not measured. Due to the small differences described above, no distinctions are noticeable between the 2D and 3D fields of temperature or humidity distribution. Even within a calculation model the beam is hardly visible. Figures 6 and 7 show 3D simulation results on January 19, 2013, a cold day with long lasting, high room humidity (average room humidity from December 2012 to March 2013 on the upper floor $=42 \%$, attic floor $=57 \%$ ).

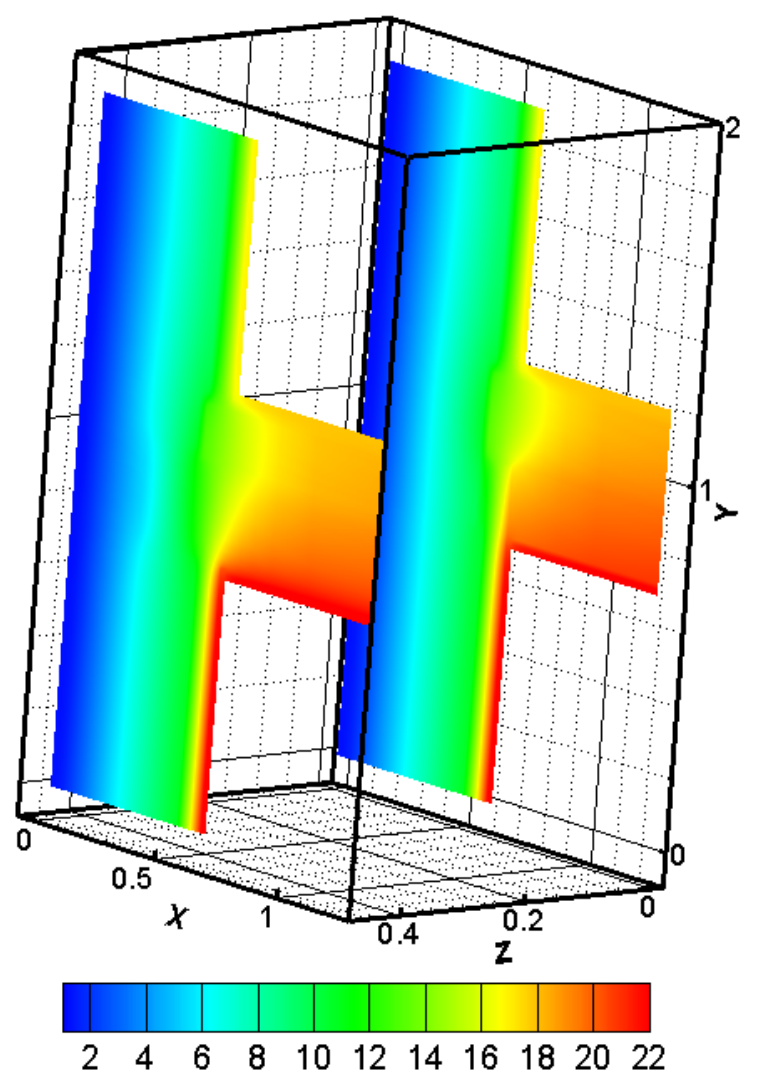

Fig. 6. Temperature field on 19 January 2013 around beam insulated with reed. Front-left section: through the middle of the beam, rear-right section: through the field (z-axis not proportional, results from $3 \mathrm{D}$ simulation, post-processing: Tecplot). 


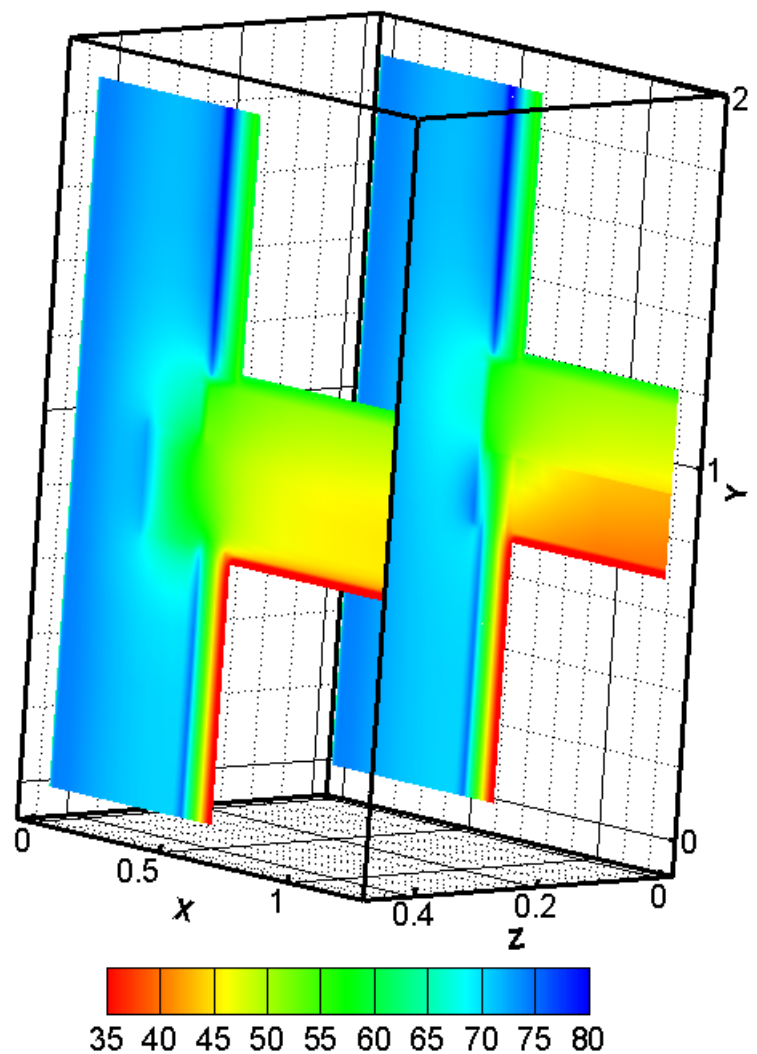

Fig. 7. Field of the relative humidity on 19 January 2013 around beam insulated with reed, without influence of air pressure. Front-left section: through the middle of the beam, back-right section: through the field (z-axis not proportional, results from 3D simulation, post-processing: Tecplot).

The influence of the wooden beam on the temperature distribution in Figure 6 is hardly noticeable. Thus, a homogeneous temperature distribution can be seen in the right section, which is located in the middle of the field, between two ceiling beams. Only at the level of the loose bulk the temperature isolines bend into the ceiling. In the left section of Figure 6, which cuts through the ceiling beam, this bulge is somewhat more extensive but not prominent. The thermal conductivity of the wooden beam is higher compared to the air layer between the beams. Therefore, here the beam pulls the isolines into the ceiling more clearly than in the section through the centre of the field. The temperature levels are also bent in the area of the air layer in front of the front wood, but only very slightly.

The humidity field allows easier localization of the wooden beam, since the two cuts in the middle of the field (back-right section in Figure 7) and through the beam (front-left section in Figure 7) are more clearly distinguished from each other.

Table 2. Average moisture difference (AD), standard deviation (s) and maximum difference $\left(\Delta_{\max }\right)$ between $2 \mathrm{D}$ and 3D calculation results with the Graz brick and a brick with higher thermal conductivity $\left(\lambda_{10, \text { dry }}=0.75 \mathrm{~W} / \mathrm{m} \cdot \mathrm{K}\right)$.

\begin{tabular}{|c|c|c|c|c|c|c|c|c|c|}
\hline & \multicolumn{3}{|c|}{$\begin{array}{c}\text { Air temperature } \\
\text { before end grain (in K) }\end{array}$} & \multicolumn{2}{c|}{$\begin{array}{c}\text { Absolute moisture of air } \\
\text { before end grain (in g/m }{ }^{3} \text { ) }\end{array}$} & \multicolumn{3}{c|}{$\begin{array}{c}\text { Wood moisture at } \\
\text { end grain (in M\%) }\end{array}$} \\
\hline & $\mathrm{AD}$ & $\mathrm{s}$ & $\Delta_{\max }$ & $\mathrm{AD}$ & $\mathrm{s}$ & $\Delta_{\max }$ & $\mathrm{AD}$ & $\mathrm{s}$ & $\Delta_{\max }$ \\
\hline$\lambda_{10, \mathrm{dry}}=0.4 \mathrm{~W} / \mathrm{m} \cdot \mathrm{K}$ & 0.281 & 0.338 & 0.791 & 0.468 & 0.552 & 1.329 & 0.370 & 0.479 & 1.141 \\
\hline$\lambda_{10, \mathrm{dry}}=0.75 \mathrm{~W} / \mathrm{m} \cdot \mathrm{K}$ & 0.246 & 0.295 & 0.710 & 0.264 & 0.309 & 0.770 & 0.180 & 0.227 & 0.528 \\
\hline
\end{tabular}

In the area of the wooden beam, the drier (green) area extends into the masonry below as well as above the wooden beam (there was no capillary breaking or diffusion-tight layer below the ceiling beams). In its immediate vicinity, the ceiling beam thus lowers the humidity, with the exception of the air layer in front of the end grain. The cold masonry surface opposite the end grain attracts and accumulates the moisture. On the other hand, in the middle of the field, the air layer between the ceiling beams is comparatively dry, with water vapour also concentrating here in the coldest area of the air layer and intruding into the construction.

\section{Further comparisons}

The bricks in the test building have an exceptionally low thermal conductivity. In a further step, the Graz bricks were therefore replaced by denser bricks (thermal conductivity $\lambda_{10 \text {, dry }}$ of 0.75 instead of $\left.0.4 \mathrm{~W} /(\mathrm{m} \cdot \mathrm{K})\right)$, in order to subsequently compare the $2 \mathrm{D}$ and $3 \mathrm{D}$ calculation results. With the change in masonry properties, no measured values are available for comparison. Therefore, the agreement between $2 \mathrm{D}$ and $3 \mathrm{D}$ simulations must be considered separately from the measured data. The evaluation of the results is based on the premise that, despite the small deviations found previously, 3D simulations results are more accurate and that larger differences are an indicator for more inaccurate 2D simulations.

Table 2 lists the deviations between 2D and 3D simulations. Three output variables are used as assessment standards: the temperature and absolute humidity at a defined point in the air layer in front of the end grain and the wood moisture at the upper, outer beam corner at a depth of approximately $10 \mathrm{~mm}$. Among all three quantities, the average difference $\mathrm{AD}$, the standard deviation s and the maximum difference $\Delta_{\max }$ are given for the entire calculation period.

According to the evaluation in Table 2, the 2D and 3D results, especially the hygric values, were even closer 
together with a higher masonry thermal conductivity of $0.75 \mathrm{~W} /(\mathrm{m} \cdot \mathrm{K})$ than with the lower measured thermal conductivity. Therefore, dynamic, hygrothermal, twodimensional simulations of beam supports are sufficient when slight inaccuracies in humidity are acceptable.

\section{Conclusions}

From this project, it could be determined that 3D simulations are not necessary to compare beam supports and do not lead to any significant improvements, especially with regard to temperatures. Both 2D and 3D simulations were able to reproduce the measurement results very well and are therefore suitable for calculating beam supports. However, with regard to humidity, 3D simulations achieved a slightly higher accuracy. The comparisons in our earlier work [11] have further shown that in the case of planning tasks, sufficient safety margins should be created, e.g. in the form of an increased internal thermal transfer resistance. This explicitly does not include the trimmer beam, which will be examined separately in the future.

The contents of this article are based on a publication in German language [16].

The OEKO-ID project was supported by the Austrian "Klimaund Energiefonds" of the FFG within the programme line "NeueEnergien 2020" and co-financed by the Styrian provincial government and the Federal Ministry for Education, Arts and Culture. Thanks to the Institute of Physics and the weather station of the Karl-Franzens-University (KFU) Graz, for providing weather data in an uncomplicated way.

\section{References}

1. T. Blomberg, Heat conduction in two and three dimensions - Computer Modelling of Building Physics Applications, Dissertation Report TVBH1008, Department of Building Physics, Lund University (1996)

2. Information about software VOLTRA on www.physibel.be/en/products/voltra

3. Information about software PSI-Therm $3 \mathrm{D}$ on www.psitherm.uk

4. Information about software ANTHERM on www.antherm.at

5. M. Janetti, F. Ochs, W. Feist, 3D Simulation of Heat and Moisture Diffusion in Constructions https://www.comsol.com/paper/download/83717/jan etti_paper.pdf requested on 25.2.2020 (2012)

6. P. Wegerer, T. Bednar, Hygrothermal performance of wooden beam heads in inside insulated walls considering air flows, EnergyProc. 132 (2017)

7. Information about software Comsol Multiphysics on https://www.comsol.de

8. Research report on https://projektinfos.energiewende bauen.de/projekt/software-zur-hygrothermischenplanung-von-baukonstruktionen/ requested on 25.2.2020 (2016)
9. Information about software DELPHIN 6 on www.bauklimatik-dresden.de

10. P. Kautsch, U. Ruisinger, H. Hengsberger, H. Steinwender, G. Dörr, K. Kukowetz, J. Ettenauer, K. Sterflinger, OEKO-ID - Innendämmungen zur thermischen Gebäudeertüchtigung Untersuchung der Möglichkeiten und Grenzen ökologischer, diffusionsoffener Dämmsysteme, Programm-linie Neue Energien 2020, Research report on https://www. energieforschung.at/assets/project/ final-report/OEKO-ID-Endbericht-web.pdf requested on 25.2.2020 (2013)

11. U. Ruisinger, Das hygrothermische Verhalten von Balkenköpfen bei innen gedämmten Gebäuden, Dissertation, TU Graz (2019)

12. S. Roels, J. Carmeliet, H. Hens, H. Brocken, C. Hall, R. Plagge, R. Cerny, Z. Pavlik, K. Kumaran, A comparison of different techniques to quantify moisture content profiles in porous building materials Therm. Env. \& Build. Sc. 27, 4 (2004)

13. L. Sontag, A. Nicolai, S. Vogelsang, Validierung der Solverimplementierung des hygrothermischen Simulationsprogramms DELPHIN, https://nbnresolving.org/urn:nbn:de:bsz:14-qucosa-128968 requested on 25.2.2020 (2013)

14. DIN EN 15026 (2007)

15. DIN EN ISO 10211 (2018)

16. U. Ruisinger, P. Kautsch, Über die Notwendigkeit dreidimensionaler, hygrothermischer Simulationen, Bauphysik 41, 295-301, 6 (2019)

17. E. Vereecken, S. Roels, Wooden beam ends in combination with interior insulation: The importance of an airtight sealing, EnergyProc. 132 (2017)

18. S. Peper, B. Zeno, A. Bangert, S. Rupps, Den Luftstrom unterbinden, $B+B$ Bauen im Bestand 6 (2013)

19. P. Kopecky, K. Stanek, M. Bures, J. Richter, J. Tywoniak, Experimental investigations of wooden beam ends in masonry with internal insulation, Energy Proc. 132 (2017)

20. P. Freudenberg, U. Ruisinger, E. Stöcker, Calibration of Hygrothermal Simulations by the Help of a Generic Optimization Tool, EnergyProc. 132 (2017)

21. WTA-Merkblatt 6-2, Simulation of heat and moisture transfer (2014) 